\title{
What works for Special Needs Students in Pakistan? Relationship between School Characteristics and Learning Outcomes
}

\author{
Muhammad Afzan Munir ${ }^{1}$, Baela Raza Jamil ${ }^{1}$, Muhammad Bilal ${ }^{2}$ \\ ITA/ASER Pakistan ${ }^{2}$ \\ Sightsavers International ${ }^{2}$
}

\begin{abstract}
School characteristics have been found to improve the learning outcomes of children. However, little research is available on the impact of school characteristics on the learning outcomes of children with disabilities. Therefore, this paper explores the relationship between school characteristics and learning outcomes of students with visual and hearing impairment in Pakistan. For this purpose, we have adapted the ASER Learning Assessment Tools into Braille and Pakistan Sign Language and have used the data from a learning outcomes survey of 20 special education public and private schools in Pakistan. Using the Ordered Logistic Model and controlling for student-specific factors such as age and gender of the child, we have found that facilities such as toilet, playground and computer lab have a positive impact on the learning outcomes of special educational needs students. In addition to this, teaching in sign language has been found to have a significant and positive impact on the learning outcomes of Deaf students. In this regard, it is recommended that Deaf students are taught in Sign Language and that all schools are equipped with facilities such as functioning toilets, playgrounds and computer labs in order to improve the learning outcomes of children with disabilities.
\end{abstract}

\section{Introduction}

The debate on how to improve the learning outcomes of children with disabilities is an ongoing one. While several researches have evaluated the impact that school characteristics have on the learning outcomes of children, less attention has been paid on the effect of school facilities on the learning outcomes of Visually Impaired and Deaf children. In this regard, we ask a fairly simple question:

Do school characteristics play a role in the learning outcomes of Special Educational Needs Students?

Therefore, this paper aims to estimate the impact that the school characteristics have on the learning outcomes of the students with visual and hearing impairments in Pakistan, while controlling for child specific factors such as age and gender of the student.

To do so, we have used the data from a survey of 20 special education schools, both public and private, in Pakistan. This survey utilized the ASER Pakistan's Learning Assessment Tools, which have been adapted into Braille and Pakistan Sign Language for the assessment of Deaf and visually impaired students, and a modified version of ASER Pakistan's School Observation Sheet.

We have found that availability of a computer lab and playground have a significant and positive impact on the learning outcomes of visually impaired students in all three subjects: English (Playground: 1.269 log-odds, Computer lab: 3.939 log-odds), Urdu (Playground: 1.217 log-odds, Computer lab: 2.803 log-odds) and Arithmetic (Playground: 2.032 logodds, Computer lab: 2.970 log-odds). Despite this, teaching through Braille and/or audio does not lead to improvements in the learning outcomes of visually impaired students.

For Deaf students, results state that teaching Deaf students in sign language, functioning toilet facility, availability of a playground and availability of a computer lab lead to an improvement in the learning outcomes of these students in English (Sign Language: 3.184 log-odds, Playground: 1.103 logodds, Computer Lab: 3.972 log-odds), Urdu (Sign Language: 2.408 log-odds, Toilet: 15.01 log-odds, Playground: 15.06 log-odds, Computer Lab: 16.92 log-odds) and Arithmetic (Sign Language: 1.890 logodds, Playground: 17.72 log-odds, Computer Lab: 2.696 log-odds) while gender (being male) tends to have an adverse effect on the learning outcomes of Deaf students in English (- 1.232 log-odds). As shown, teaching Deaf students in sign language improves their learning outcomes.

Therefore, this paper will not only further our understanding about the factors that affect the learning outcomes of CWDs in Pakistan, but will also provide us with key policy insights regarding the matter at hand.

\section{Literature Review}

Researchers have long been exploring the relationship between the schooling and the learning 
outcomes of children and have found that school characteristics tend to have a significant impact on the educational attainment and learning outcomes of children. Schneider [1] has reviewed various sources of school characteristics that may have a direct or an indirect effect on child's development and found that clean air, good light, comfortable environment, small school size and provision of other school facilities tend to have a positive impact on the learning outcomes of children. Absence of these facilities have an adverse effect on the performance of not only students but of teachers as well: poor indoor air quality makes students and teachers sick while larger school sizes are associated to a lower student achievement. Moreover, Uline [2], based on the survey of 80 middle schools in Virginia USA, have found that the quality of school facilities has a positive impact on the learning outcomes of students with regards to English and Mathematics. School facilities contribute to the learning outcomes through the channel of school climate whereby improved school facilities lead to an improved school climate. This, consequently, leads to an improvement in the learning outcomes of students in English and Mathematics. Similarly, studies have found that a school's physical environment has a positive impact on students' achievement [3].

Not only this, supportive school and classroom environment can also be used as a tool to reduce the achievement gap among students from varying socio-economic backgrounds. Berkowitz et al. [4] have reviewed the studies on this subject and have found that, although a causal link has not been established, positive school climate has been found to mitigate the differences arising in academic achievement due to socioeconomic status of students. Realizing the need for this, governments and development organizations have been working actively towards the provision of a learning-enabled environment for students in schools.

While several studies have explored the link between school characteristics and learning outcomes of students enrolled in the mainstream education system, only few have focused on this relationship from the perspective of special educational needs (SEN) students. In addition to this, none has empirically explored the impact of school characteristics on the learning outcomes of SEN students in Pakistan. In this regard, our research will prove to be useful in informing the future studies.

\section{Methodology}

This section provides information on the methodology which we employ for our quantitative analysis. In our main model of interest, we regress SEN students' learning outcomes (English, Urdu, Arithmetic) on the school characteristics, which include mode of instruction: sign language (for
Deaf), mode of instruction: braille/audio (for Visually Impaired), school has library books, school has a functioning toilet and school has a computer lab, and child characteristics (gender and age) using Ordered Logistic Model. Child characteristics (gender and age) have been added as control variables in our model. We apply the following models separately to students with hearing and visual impairments.

In our main model i.e. Model 1, we regress the learning outcomes of the sampled students on the mode of instruction, school characteristics and child characteristics.

$$
\begin{gathered}
\text { Learning Outcome } \\
\text { Ochool }_{i}+\beta_{3} \text { Child }_{i}+u
\end{gathered}
$$

Where:

Learning Outcome $_{i}=$ Learning Level attempted correctly by a child $\mathrm{i}$

Mode_Instruct $\mathrm{i}_{\mathrm{i}}=$ Mode of Instruction in which a child is being taught $\mathrm{i}$

School $_{i}=$ Characteristics/Facilities in school in which a child is enrolled $i$

Child $_{\mathrm{i}}=$ Characteristics of a Child $\mathrm{i}$

In Model 2, we regress the learning outcomes of the sampled students on the mode of instruction and the school characteristics to check for the robustness of our estimates.

$$
\begin{gathered}
\text { Learning Outcome }{ }_{\mathrm{i}}=\alpha+\beta_{1} \text { Mode_Instruct }_{\mathrm{i}}+\beta_{2} \\
\text { School }_{\mathrm{i}}+\mathrm{u}
\end{gathered}
$$

Since our dependent variable is a categorical variable with categories ordered in an ascending order i.e. from lowest learning outcomes to highest learning outcomes, we have used the Ordered Logistic Model, with robust standard errors, for regression analysis.

\section{Data}

This paper draws on the data which was collected through Idara-e-Taleem-o-Agahi's project, namely "Inclusive Assessments through Partnerships -ASER Tools Adaptation for the Deaf and Visually Impaired - Mapping SDG 4 for inclusion and equity". Under this project, ASER Pakistan's Learning Assessment Tools for the mainstream children were adapted into Braille (adapted by Sightsavers International) and Pakistan Sign Language (adapted by Family Educational Services Foundation) for the assessment of Visually Impaired and Deaf children, respectively. The adapted tools were then piloted across two 
provinces of the country: Punjab and Sindh in 20 government, private and NGO-run schools.

From each school, a sample of 10 to 12 students was randomly selected from Grades 1 to 5 for Deaf students and Grade 1 to 8 for Visually Impaired students. It is important to note that ASER Learning Assessment Tools assess the basic competencies of children at grade 2 level of country's national curriculum in English, Urdu and Arithmetic.

After the assessment, the students were marked using the following scale (see Table 1) with rows 5 and 6 showing the highest level competencies for the respective subject. For example, if a student was unable to recognize 4 out of 5 common letters in the Urdu assessment, that child was marked as a beginner in Urdu. Similarly, in the Arithmetic assessment, if the child could not even recognize 4 out of 5 numbers from the 1 to 9 number recognition list, that child was marked at the Beginner level.

Table 1. Assessment Scale

\begin{tabular}{|c|c|c|c|}
\hline & English & Urdu & Arithmetic \\
\hline 1 & Beginner & Beginner & Beginner \\
\hline 2 & $\begin{array}{l}\text { Capital } \\
\text { Letters }\end{array}$ & Letters & $\begin{array}{c}\text { Number Recognition } \\
(1-9)\end{array}$ \\
\hline 3 & $\begin{array}{l}\text { Small } \\
\text { Letters }\end{array}$ & Words & $\begin{array}{c}\text { Number Recognition } \\
(10-99)\end{array}$ \\
\hline 4 & Words & Sentences & $\begin{array}{c}\text { Number Recognition } \\
(100-200)\end{array}$ \\
\hline 5 & Sentences & Story & Subtraction \\
\hline 6 & - & - & 2-Digit Division \\
\hline
\end{tabular}

In addition to the assessment of special needs students (Deaf and Visually Impaired), we also collected information on school facilities and other school characteristics by using the school observation sheet while also collecting information on child characteristics such as gender and age. All questions were asked from the head teachers to ensure that authenticated responses were recorded from those who had most information about the respective school. Descriptive statistics of the variables which we have used in our analysis are given in Table 2 (Deaf students) and Table 3 (Visually Impaired students).

We had a sample of 106 Deaf students within the age group of 6 to 16 years with the mean age being 10.62 years. Majority of the Deaf students $(66 \%)$ were boys while the rest were girls $(34 \%)$. $65 \%$ of the surveyed schools for Deaf students claimed to be teaching the enrolled students in sign language. Moreover, most of the schools for Deaf children had a useable toilet facility (91.5\%), playground (93\%) and computer lab (84.9\%). It is interesting to see that the highest learning level that the Deaf students were able to achieve in Urdu was the words level (Level $3)$.
Table 2. Summary Statistics - Deaf

\begin{tabular}{|l|c|c|c|c|c|}
\hline & $(1)$ & $(2)$ & $(3)$ & $(4)$ & $(5)$ \\
\hline VARIABLES & $\mathrm{N}$ & mean & Sd & Min & $\max$ \\
\hline $\begin{array}{l}\text { Mode_Instruct_De } \\
\text { af }\end{array}$ & 98 & 0.653 & 0.478 & 0 & 1 \\
\hline School_Toilet & 106 & 0.915 & 0.280 & 0 & 1 \\
\hline School_Playground & 106 & 0.934 & 0.250 & 0 & 1 \\
\hline School_Comp_Lab & 106 & 0.849 & 0.360 & 0 & 1 \\
\hline Child_Gender & 106 & 0.660 & 0.476 & 0 & 1 \\
\hline Child_Age & 106 & 10.62 & 2.408 & 6 & 16 \\
\hline English_Level & 102 & 2.618 & 1.275 & 1 & 5 \\
\hline Urdu_Level & 102 & 1.255 & 0.624 & 1 & 3 \\
\hline Arithmetic_Level & 98 & 3.459 & 1.574 & 1 & 6 \\
\hline
\end{tabular}

With respect to the sample of visually impaired students, we had a total of 90 students with the mean age of 13.28 years. $57 \%$ of the visually impaired students in our sample were boys and the remaining $43 \%$ were girls.

Table 3. Summary Statistics - Visually Impaired

\begin{tabular}{|l|c|c|c|c|c|}
\hline & 1 & $(2)$ & $(3)$ & $(4)$ & $(5)$ \\
\hline VARIABLES & $\mathrm{N}$ & Mean & sd & $\min$ & $\max$ \\
\hline Mode_Instruct_VI & 82 & 0.927 & 0.262 & 0 & 1 \\
\hline School_Toilet & 90 & 1 & 0 & 1 & 1 \\
\hline School_Playground & 90 & 0.400 & 0.493 & 0 & 1 \\
\hline School_Comp_Lab & 90 & 0.722 & 0.450 & 0 & 1 \\
\hline Child_Gender & 90 & 0.567 & 0.498 & 0 & 1 \\
\hline Child_Age & 90 & 13.28 & 3.660 & 5 & 24 \\
\hline English_Level & 85 & 4.141 & 1.146 & 1 & 5 \\
\hline Urdu_Level & 84 & 4.048 & 1.231 & 1 & 5 \\
\hline Arithmetic_Level & 89 & 4.416 & 1.744 & 1 & 6 \\
& & & & & \\
\hline
\end{tabular}

Among the surveyed schools for visually impaired, 92\% were teaching the enrolled students through Braille and/or Audio, $100 \%$ had a useable toilet facility, only $40 \%$ had a playground and $72 \%$ had a functioning computer lab. Means of the learning outcomes in English, Urdu and Arithmetic show that 
visually impaired students were marked at or above Level 4, on average.

\section{Results and Discussion}

This section reports the results which we have obtained through the Ordered Logistic Model presented in section 2 .

Tables 4, 5 and 6 cover the results for the visually impaired students in English, Urdu and Arithmetic, respectively.

Table 4. Results for Visually Impaired Students English

\begin{tabular}{|l|l|l|}
\hline & $(1)$ & $(2)$ \\
\hline VARIABLES using & English & English \\
\hline $\begin{array}{l}\text { Taught } \\
\text { Braille/Audio }\end{array}$ & -0.507 & \\
\hline & $(1.051)$ & $(0.967)$ \\
\hline School_Toilet & - & - \\
\hline & & \\
\hline School_Playground & $1.269 * *$ & $1.013 *$ \\
\hline & $(0.554)$ & $(0.523)$ \\
\hline School_Computer_Lab & $3.939 * * *$ & $3.958 * * *$ \\
\hline & $(0.805)$ & $(1.015)$ \\
\hline Child_Age & $0.189 *$ & \\
\hline & $(0.106)$ & \\
\hline Child_Gender & -0.180 & \\
\hline & $(0.618)$ & \\
\hline Observations & 77 & 77 \\
\hline
\end{tabular}

Robust standard errors in parentheses $* * * \mathrm{p}<0.01, * * \mathrm{p}<0.05, * \mathrm{p}<0.1$

Table 4 shows that having a school playground leads to a 1.269 increase in the log-odds of being at a higher level of learning outcomes for English. Similarly, computer labs tend to have a more profound and significant impact on the log-odds of being at a higher level of learning outcomes in English: computer lab leads to an increase of 3.939 log-odds of a child being at a higher level of learning outcomes in English. These estimates have been found to be robust in nature as shown in column 1 and column 2 .

Furthermore, Table 5 depicts that school playground increases the log-odds of a child being at a higher level of learning outcomes in Urdu by 1.217; availability of a computer lab leads to an increase of 2.803 in log-odds of a child being at a higher level of learning outcomes in Urdu. Column 1 and 2 show that, controlling for child's age and gender, the impact of a school playground becomes significant while the significance of the estimate for computer lab remains unchanged. Therefore, these estimates are robust.
Table 5. Results for Visually Impaired Students Urdu

\begin{tabular}{|l|l|l|}
\hline & $(1)$ & $(2)$ \\
\hline VARIABLES using & -0.597 & Urdu \\
\hline $\begin{array}{l}\text { Taught } \\
\text { Braille/Audio }\end{array}$ & -1.638 \\
\hline & $(1.305)$ & $(1.054)$ \\
\hline School_Toilet & - & - \\
\hline & & \\
\hline School_Playground & $1.217 * *$ & 0.847 \\
\hline & $(0.586)$ & $(0.530)$ \\
\hline School_Computer_Lab & $2.803 * * *$ & $3.181 * * *$ \\
\hline & $(0.947)$ & $(1.156)$ \\
\hline Child_Age & $0.258 * *$ & \\
\hline & $(0.130)$ & \\
\hline Child_Gender & -0.0431 & \\
\hline & $(0.664)$ & \\
\hline Observations & 76 & 76 \\
\hline
\end{tabular}

Robust standard errors in parentheses $* * * \mathrm{p}<0.01, * * \mathrm{p}<0.05, * \mathrm{p}<0.1$

We find similar results regarding visually impaired students' performance in Arithmetic (Table 6). School Playground has a positive and significant impact on the log-odds of a visually impaired student being at a higher level of learning outcome in Arithmetic, the magnitude for which is 2.032 . Likewise, availability of a computer lab in school tends to increase the log-odds by 2.970 .

Table 6. Results for Visually Impaired StudentsArithmetic

\begin{tabular}{|l|l|l|}
\hline & $(1)$ & $(2)$ \\
\hline VARIABLES & Arithmetic & Arithmetic \\
\hline $\begin{array}{l}\text { Taught using } \\
\text { Braille/Audio }\end{array}$ & -2.411 & -2.549 \\
\hline & $(2.224)$ & $(1.719)$ \\
\hline School_Toilet & - & - \\
\hline $\begin{array}{l}\text { School_Playgroun } \\
\text { d }\end{array}$ & $2.032 * * *$ & $1.382 * *$ \\
\hline & $(0.596)$ & $(0.561)$ \\
\hline School_Computer & $2.970 * * *$ & $2.512 * * *$ \\
\hline Lab & & 81 \\
\hline & $(0.634)$ & $(0.704)$ \\
\hline Child_Age & $0.276 * * *$ & \\
\hline & $(0.0911)$ & \\
\hline Child_Gender & 0.160 & \\
\hline Observations & $(0.435)$ & \\
\hline
\end{tabular}

Robust standard errors in parentheses $* * * \mathrm{p}<0.01, * * \mathrm{p}<0.05, * \mathrm{p}<0.1$ 
Availability of a toilet facility in school has been omitted from our results for visually impaired as all schools for visually impaired students had a toilet.

In addition to this, instructional material in Braille and Audio turns out to have a negative impact on the learning outcomes, but since the estimates for that are insignificant, we can assume that having instructional material in Braille/Audio has no effect on the learning outcomes of visually impaired students. This is true for all three subjects: English, Urdu and Arithmetic.

Equally important is the impact of school characteristics on the learning outcomes of Deaf students. These estimates are recorded in Tables 7, 8 and 9 for English, Urdu and Arithmetic, respectively.

As shown in Table 7, we have found that teaching in Sign Language leads to an increase of $3.184 \mathrm{log}$ odds in the learning outcomes of Deaf students in English. Similarly, playgrounds and computer labs tend to have a significant impact on the log-odds of being at a higher level of learning outcomes in English: playground leads to an increase of 1.013 log-odds (significant at $10 \%$ level of significance) while availability of computer lab has a more profound and positive impact on the log-odds (increase of $3.972 \mathrm{log}$-odds which is significant at $1 \%$ level of significance).

On the other hand, gender of child may negatively affect the learning outcomes of Deaf students: if a child is male, his log-odds of being at a higher level of learning outcome in English tends to decrease by 1.232 log-odds, on average.

Table 7. Results for Deaf Students - English

\begin{tabular}{|c|c|c|}
\hline & (1) & (2) \\
\hline VARIABLES & English & English \\
\hline \multirow[t]{2}{*}{$\begin{array}{lll}\text { Taught } & \text { using } & \text { Sign } \\
\text { Language } & & \\
\end{array}$} & $3.184 * * *$ & $3.124 * * *$ \\
\hline & $(0.658)$ & $(0.644)$ \\
\hline \multirow{2}{*}{ School_Toilet } & 0.450 & 0.154 \\
\hline & $(0.876)$ & $(0.850)$ \\
\hline \multirow[t]{2}{*}{ School_Playground } & $1.013^{*}$ & 0.445 \\
\hline & $(0.598)$ & $(0.588)$ \\
\hline \multirow[t]{2}{*}{ School_Computer_Lab } & $3.972 * * *$ & $4.071 * * *$ \\
\hline & $(0.801)$ & $(0.789)$ \\
\hline \multirow[t]{2}{*}{ Child_Age } & $0.171 *$ & \\
\hline & $(0.0872)$ & \\
\hline \multirow[t]{2}{*}{ Child_Gender } & $-1.232 * * *$ & \\
\hline & $(0.463)$ & \\
\hline Observations & 94 & 94 \\
\hline
\end{tabular}

Column 1 of Table 8 shows that teaching in Sign Language leads to an increase of 2.408 log-odds in the learning outcomes of Deaf students in Urdu. The impact of a toilet facility, playground and computer lab is even more significant: availability of toilet increases the log-odds by 15.01 log-odds (significant at $10 \%$ level of significance), playground increases the log-odds by 15.06 log-odds (significant at $10 \%$ level of significance) and availability of a computer lab tends to increase the log-odds of Deaf students of being at a higher level of learning outcome in Urdu by 16.92 log-odds (significant at $10 \%$ level of significance), on average. Availability of toilet, playground and computer lab was insignificant in the basic model (column 2), however once we have controlled for child-specific characteristics, our estimates become significant.

Table 8. Results for Deaf Students - Urdu

\begin{tabular}{|l|l|l|}
\hline & $(1)$ & $(2)$ \\
\hline VARIABLES & Urdu & Urdu \\
\hline $\begin{array}{l}\text { Taught using Sign } \\
\text { Language }\end{array}$ & $2.408^{*}$ & $2.190^{* *}$ \\
\hline & $(1.278)$ & $(1.037)$ \\
\hline School_Toilet & $15.01^{* * *}$ & 15.54 \\
\hline & $(1.167)$ & \\
\hline School_Playground & $15.06^{* * *}$ & 15.54 \\
\hline & $(0.967)$ & \\
\hline School_Computer_Lab & $16.92^{* * *}$ & 17.73 \\
\hline & $(0.381)$ & \\
\hline Child_Age & 0.204 & \\
\hline & $(0.148)$ & \\
\hline Child_Gender & -0.456 & \\
\hline & $(0.609)$ & \\
\hline Observations & 94 & 94 \\
\hline
\end{tabular}

Robust standard errors in parentheses $* * * \mathrm{p}<0.01, * * \mathrm{p}<0.05, * \mathrm{p}<0.1$

Table 9. Results for Deaf Students - Arithmetic

\begin{tabular}{|c|c|c|}
\hline VARIABLES & $\begin{array}{l}\text { (1) } \\
\text { Arithmetic }\end{array}$ & $\begin{array}{l}(2) \\
\text { Arithmetic }\end{array}$ \\
\hline $\begin{array}{l}\text { Taught using Sign } \\
\text { Language }\end{array}$ & $1.890 * * *$ & $1.432 * * *$ \\
\hline School_Toilet & $\begin{array}{l}0.437 \\
(0.652)\end{array}$ & $\begin{array}{l}0.629 \\
(0.635)\end{array}$ \\
\hline School_Playground & $\begin{array}{l}17.72 * * * \\
(0.700)\end{array}$ & $\begin{array}{l}16.09 * * * \\
(0.581)\end{array}$ \\
\hline School_Computer_Lab & $\begin{array}{l}2.696 * * * \\
(0.960)\end{array}$ & $\begin{array}{l}2.549 * * * \\
(0.833)\end{array}$ \\
\hline Child_Age & $\begin{array}{l}0.148^{*} \\
(0.0901)\end{array}$ & \\
\hline Child_Gender & $\begin{array}{l}0.649 \\
(0.548)\end{array}$ & \\
\hline Observations & 90 & 90 \\
\hline
\end{tabular}

Robust standard errors in parentheses $* * * \mathrm{p}<0.01, * * \mathrm{p}<0.05, * \mathrm{p}<0.1$

Lastly, we observe that teaching in sign language, playground and availability of a computer lab have a significant and positive impact where these schoolspecific characteristics lead to an increase of 1.890 , 
17.72 and 2.696 log-odds in the learning outcomes of Deaf students in Arithmetic, respectively.

Using sign language as a medium of instruction has been found to be effective in improving the learning outcomes of Deaf students. The magnitudes of estimates for teaching in sign language are greater for English and Urdu when compared with that for Arithmetic. Nonetheless, all three estimates are significant.

\section{Conclusion}

This study has found that playground in school, availability of computer lab and child's age contribute positively and statistically significantly towards the learning outcomes of visually impaired students. With school having a playground, we would expect $1.217,1.269$ and 2.032 increase in the log-odds of being at a higher level of learning outcomes for Urdu, English and Arithmetic, respectively. It is interesting to see that the increase in log-odds is almost two times for learning outcomes in Arithmetic when compared with English and Urdu. Computer lab in school also leads to an increase of 2.803 (Urdu), 3.939 (English) and 2.970 (Arithmetic) log-odds in the learning outcomes. Similarly, older age of a child also has a positive impact on the learning outcomes of that particular child. The availability of instructional material in Braille and Audio does not affect the learning outcomes of visually impaired students.

Moreover, estimates for Deaf students provide empirical evidence that teaching in Sign Language positively affects the learning outcomes of Deaf students. The estimates for which are statistically significant and are found to be 2.408 (Urdu), 3.184 (English) and 1.890 (Arithmetic) i.e. teaching in sign language leads to positive impact on the log-odds of a Deaf student being at a higher learning level. Useable Toilet facility on school premises was found to have a positive effect on the Urdu learning outcomes i.e. an increase of $15.01 \mathrm{log}$-odds in the Urdu learning outcomes. Moreover, playground and computer lab in school also has a positive and a significant impact on the learning outcomes of Deaf students. Contrary to the results for visually impaired students, child's age only has an impact on the English and Arithmetic components of learning while being a male reduces the log-odds by 1.232 in English.

These results show that Sign language improves the learning outcomes of Deaf children. Hence, there is a need to promote the use of the sign language as a medium of instruction for Deaf children.

In addition to this, availability of a toilet facility, playground and computer lab have also shown to have a positive impact on the learning outcomes of both Deaf and visually impaired children. Therefore, provision of such facilities will only increase the learning outcomes of children with disabilities.

\section{References}

[1] M. Schneider, "Do School Facilities Impact Academic Outcomes?", National Clearinghouse for Educational Facilities, Washington DC, 2002.

[2] C. Uline and M. Tschannen-Moran, "The walls speak: the interplay of quality facilities, school climate, and student achievement", Journal of Educational Administration, 2008, 46(1), pp. 55-73.

[3] C.K. Tanner, "Explaining Relationships Among Student Outcomes and the School's Physical Environment" Journal of Advanced Academics, 2008, 19(3), pp. 444-471.

[4] R. Berkowitz, H. Moore, R. A. Astor and R. Benbenishty, "A Research Synthesis of the Associations Between Socioeconomic Background, Inequality, School Climate, and Academic Achievement", Review of Educational Research, 2017, 87(2), pp. 425-469. 